\title{
THE TREATMENT OF THE PARALYSED BLADDER AFTER SPINAL INJURY IN THE ACCIDENT UNIT OF COLMAR
}

\author{
P. Dollfus, M.D., and L. MolÉ, M.D.
}

SINCE the early part of 1967 we decided to use for all our tetra- and paraplegic patients the same method of treatment as is in use in the National Spinal Injuries Centre, Stoke Mandeville Hospital.

One great advantage is that a large number of our patients are treated immediately after the accident, either in the resuscitation unit or in the wards. Intermittent catheterisation has been our method of choice for bladder paralysis; it is performed on male patients by a medical officer and, for female patients, by a fully trained nurse. The introduction of intermittent catheterisation in a Traumatology Centre was certainly not as difficult as may have been thought. Certain difficulties were encountered initially: teaching the proper technique to a 24 -hour rotating medical staff, preparation of the sterile material, and the necessity for the frequent availability of medical staff.

The psychological approach of the medical staff as a whole is most important, but is, in fact, the same approach that is required to teach those with little previous clinical experience in paraplegia how to prevent sores.

Only once, in the three last years, has an indwelling catheter been used, for a maximum period of 48 hours (except for patients admitted with one, which was usually soon removed).

The following tables are extracted from the thesis of one of our interns, Dr. Jacob-Chia who is continuing his training under the supervision of Dr. Paeslack in Heidelberg (date of thesis I3.3.69).

The results appear to be most encouraging, considering that they cover the period of the first three or four months after injury; 82 per cent. of the urines were sterile in men, and 67 per cent. in women. The residual urine, in most of our cases, was less than $50 \mathrm{ml}$. at the time of discharge.

More encouraging are the provisional results obtained in our last three patients, all men, two incomplete cervicals and one complete lumbar lesion, not mentioned in the above tables and for whom we decided not to give any antibiotic cover. The urine has remained sterile for an initial period of more than 9, I2 and I6 weeks respectively, infection occurring only temporarily in two patients; the other, a case of a very incomplete cervical lesion, having recovered satisfactory bladder control after nine weeks of intermittent catheterisation remained uninfected after discharge to the Rehabilitation Centre of Mulhouse. The other two have been since discharged with sterile urine. We have been able to follow up i4 patients after discharge, some for more than two years, and have found that 92 per cent. have kept their urine sterile. Although percentages, in such a small series can very questionable, the outlook is encouraging.

We consider that these excellent results are the fruit of the work and teaching of Sir Ludwig Guttmann, to whom we offer our very best wishes and Many Happy Returns of the Day! 
TABLE I

Women

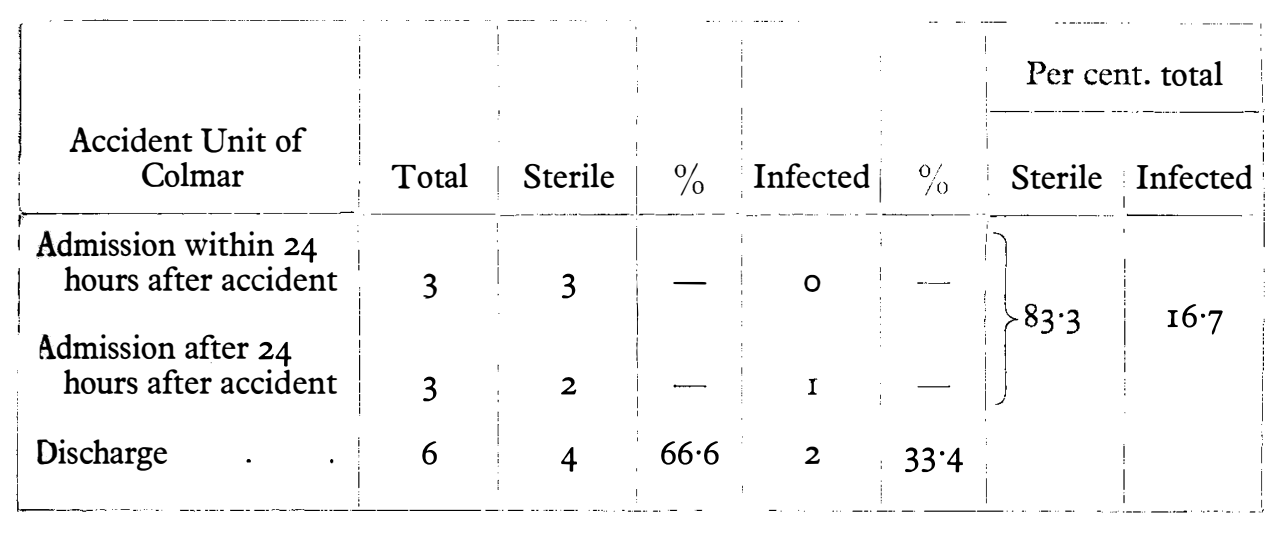

TABLE II

Men

\begin{tabular}{|c|c|c|c|c|c|c|c|}
\hline \multirow[b]{2}{*}{$\begin{array}{l}\text { Accident Unit of } \\
\text { Colmar }\end{array}$} & \multirow[b]{2}{*}{ Total } & \multirow[b]{2}{*}{ Sterile } & \multirow[b]{2}{*}{$\%$} & \multirow[b]{2}{*}{ Infected } & \multirow[b]{2}{*}{$\%$} & \multicolumn{2}{|c|}{ Per cent. total } \\
\hline & & & & & & Sterile & Infected \\
\hline $\begin{array}{l}\text { Admission within } 24 \\
\text { hours after accident }\end{array}$ & 13 & I 2 & $92 \cdot 3$ & I & $7 \cdot 7$ & $84 \cdot 2$ & I 5.8 \\
\hline $\begin{array}{l}\text { Admission after } 24 \\
\text { hours after accident }\end{array}$ & 6* & $4 \dagger$ & $66 \cdot 6$ & $2 f$ & $33 \cdot 4$ & & \\
\hline Discharge $\$$ & I7 & I4 & $82 \cdot 3$ & 3 & $17 \cdot 7$ & & \\
\hline & $\begin{array}{l}* 5 \\
\dagger 3 \\
\dagger 2 \\
\dagger 2 \\
\$ 1\end{array}$ & $\begin{array}{l}\text { with in } \\
\text { with in } \\
\text { with in } \\
\text { in hosp }\end{array}$ & $\begin{array}{l}\text { velling } \\
\text { velling } \\
\text { velling } \\
1 \text { and }\end{array}$ & $\begin{array}{l}\text { catheter. } \\
\text { catheter. } \\
\text { catheter. } \\
\text { ceased. }\end{array}$ & & & \\
\hline
\end{tabular}

